\title{
Machine Learning for Nano-scale Particulate matter distribution from Gasoline Direct Injection Engine
}

\author{
Yi-Hao Pu, Jayanth Keshava Reddy, Stephen Samuel
}

Department of Mechanical Engineering and Mathematical Sciences, Oxford Brookes University, Oxford, UK

Address correspondence to Stephen Samuel, Faculty of Technology, Design \& Environment, Department of Mechanical Engineering and Mathematical Sciences, Oxford Brookes University, Wheatley Campus, OX33 1HX,United Kingdom.

Phone: + 441865 483513; email: s.samuel@brookes.ac.uk

\section{ABSTRACT}

Predicting the amount of combustion generated nano-scale particulate matter (PM) emitted by gasoline direct injection (GDI) is a challenging task, but immensely useful for engine calibration engineers in order to meet the stringent emission legislation norms. The present work aimed to link the in-cylinder combustion with engine-out nano-scale PM for the size range of 23.7 to $1000 \mathrm{~nm}$ diameter. Neural network with a single hidden layer using first 8 principal components of cylinder pressure was employed for training and predicting the number of nano-scale PM number count. Using a systematic computational approach and comparing its results with experimental data this work demonstrates that machine-learning approach based on neural network is sufficient for predicting engine out nano-scale PM count as a function of engine load and speed.

KEYWORDS: Nano-scale particulate matter, Gasoline direct injected engine, Machine learning, Principal component analysis

\section{INTRODUCTION}

Ever since the relationship between the combustion generated pollutants and adverse health impact was established [1], identifying the source of pollution and limiting the levels of pollutants have become a major task. The internal combustion engines mainly used in automotive applications are the main contributors to the increased levels of air pollution in major cities. The definition of types of pollutants, their levels and their link with human health has also been changing over the time. Several factors have contributed to these changes. Firstly, the understanding of the formation mechanism of these pollutants has improved over time. Secondly, more evidence has emerged over time linking the toxicity of these pollutants with adverse human health. Thirdly, technological advances in measurement technology in the field of aerosol measurement have enabled researchers to measure ultrafine particles in-situ, which was not possible in the past. Finally, it has become possible to model and calibrate the engine system to meet stringent emission targets.

For example, European commission introduced test protocol and target values for permissible levels of exhaust Carbon Monoxide (CO) and Hydrocarbon (HC) [2]. Since then new pollutants have been added to the list [3]. One of the pollutants recently added to the list is the number count of the nano-scale PM from gasoline-powered engines. Legislation since 1972 [4] specially included the link between diesel engine and smoke generated by 
combustion process in engine. Amendments to the EU legislation for vehicle emission 70/EEC/220 was introduced in 1980s to include the PM emitted from diesel engine [5]. It has been measured in term of $\mathrm{mg} / \mathrm{m}^{3}$ using the sample taken from tailpipe. This measurement aimed to capture the lower end size of $P M$ down to $10 \mu m\left(P_{10}\right)$ and then later 2.5 $\mu \mathrm{m}\left(\mathrm{PM}_{2.5}\right)$ [6]. Until 2014, these were applicable only for PM from diesel engines. However, the improvement in nano-technology, especially real-time in-site measurement of nano-scale PM from the internal combustion engines down to $5 \mathrm{~nm}$ diameter have enabled the legislators to introduce the legislation aimed at reducing the number count of smaller PM of size range $1 \mathrm{~nm}-1000 \mathrm{~nm}$ diameter. It was identified by many researchers that most of the submicron particles produced during combustion process, especially, originate from gasoline combustion are less than $100 \mathrm{~nm}$ diameter $[7,8]$ and are more harmful to human beings and animals than the larger submicron particles [9]. Many studies have demonstrated the adverse health impact of nano-scale particles that originate from combustion on human health [10]. Current legislation for gasoline engine [11] requires the vehicle manufacturer to calibrate the engine for the target PM count of $6 \times 10^{6}$ particles per $\mathrm{km}$ at the tailpipe-out location. Even though modern gasoline engines with direct fuel injection systems offer excellent fuel economy benefits over their indirect injection counterparts, it still need to overcome major challenges in order to meet the target set for amount of nano-scale PM. The main challenges are the knowledge gaps that exist in the detailed formation mechanisms of nano-scale PM.

Various researchers have been investigating the correlation among the engine operating variables [12-15] such as injection timing, spark timing, air-fuel ratio and engine operating temperature to the formation mechanism of nano-scale PM, especially at the tailpipe-out location. The major factors influencing the formation of PM were injection timing and engine operating temperature especially in a wall-guided GDI engine. They observed a strong relationship between fuel impingement determined by the timing of start of injection and increased levels of nano-scale PM.

The next stage in the investigation of nano-scale PM is to identify the correlation between in-cylinder combustion characteristics and formation mechanism of nano-scale PM [16-20]. Experimental studies were able to correlate the stages of combustion such as 5, 10, 50 and $90 \%$ mass fraction burned with total number of PM in different size range. Correlation of temporal oscillations of engine-out particle number count and cycle-by-cycle variations of cylinder pressure in GDI engines was also observed [7]. In addition, numerous studies focusing on the effect of exhaust gas re-circulation (EGR) on PM [21-24], injector characteristics and the effect of mixture qualities [25, 26] on PM can be found in the literature. However, a proper and detailed method to model the mechanism of the nano-scale PM formation from gasoline engine based on the experimental or numerical observations is not available in the published domain.

It is also known that three-way catalysts (TWC) influence the distribution of nano-scale PM and change the distribution pattern depending upon the engine operating conditions and the catalytic converter conditions at the time of operation. Preliminary studies based on experimental observations available in the published literature indicate that the catalytic converter influences different particle size ranges differently during steady state as well as during cold start engine operating conditions $[27,28]$. However, very limited number of studies are available in the public domain from a variety of engines and types of catalytic converter. Therefore, it is not possible to draw any generalized conclusion about the influence of TWC on engine out nano-scale PM from GDI engine other than 
highlighting the non-linearity introduced by the catalytic converters. Similarly, very little is known on the role of turbocharger on changing the characteristic of nano-scale particulate matter to date [29]. Further work from Cucchi et al. [30] also showed that the influence of turbocharger on engine out nano-scale PM could be modelled using Lambert $\mathrm{W}$ function. The literature highlights that unless the effect of catalytic converter and turbochargers are included, the chances for developing correlations between the in-cylinder combustion characteristics with the tailpipe-out PM levels are very limited. Hence, the current work uses the engine-out particulate characteristics measured upstream of the turbocharger for the analysis.

Developing calibration schemes based on measured combustion characteristics for the control of nano-scale PM is one of the viable options for GDI engines [31]. Measurement methodology and choosing the conditions for sampling and measuring engine - or tailpipe-out nano-scale PM is another key factor in quantifying nano-scale PM count. Unlike the high repeatability of gaseous emission levels measured at the tailpipe, nano-scale particulate count measured at the tailpipe is found to vary significantly from vehicle to vehicle, and even the same vehicle at different laboratories can have diverse results due to various measurement set-up and other unknown conditions [32, 33]. This statistical variability is not consistent even across the entire size ranges [31, 34]; for example, the particle size range less than $23 \mathrm{~nm}$ seems to be less repeatable and prone to have more variations based on the dilution parameters chosen for the measurement. Counting efficiency of the weight given for the particles less than $23 \mathrm{~nm}$ is only $50 \%$, since, the particles size range below $23 \mathrm{~nm}$ diameter may not come from the combustion but instead may be caused by nucleation during the dilution process. In addition, the regulations also allow the manufacturers to choose wide dilution ratio for the type approval of their vehicle for particulate certification [35].

Therefore, optimizing the engine combustion performance in order to meet the tailpipe-out particulate number count requires the particulate count only due to combustion. Choosing the sampling point upstream of the catalytic converter will enable us to remove the effect of turbocharger as well as the catalytic converter. However, it is hard to remove the effect of measurement system itself. By choosing appropriate dilution ratio, the repeatable measurement is achievable, and can be used for developing combustion strategy to control the engine-out PM number count.

Developing the prediction model for tailpipe-out nano-scale particulate count is essential for estimating the tailpipe-out PM levels against legislative drive cycles. In addition, if the prediction models are based on variables that govern combustion characteristics, it is possible to develop suitable combustion control strategy for optimizing the engine out PM levels. It is already known from the limited amount of literature that it is not possible to predict the total count of PM at tailpipe-out without including the effect of turbocharger and TWC. Since, the behaviour of the catalytic converters and the turbochargers are not fully known, the only viable option at this stage is to develop a prediction model for nano-scale particulate count at engine-out (upstream of the turbocharger) position.

Real time prediction of particle distribution based on the engine operating conditions for diesel engine have been demonstrated by Scafati et al. [36]. Scafati et al employed neural network to predict the particle distribution for the size range of 8 to $381 \mathrm{~nm}$ diameter as a function of engine speed, load and EGR for a diesel engine. Their model was capable of predicting particle distribution with the absolute square mean error of 3-7\%. Ample evidence could be found in the literature in relation to application of neural network for predicting the behaviours of diesel particulate 
filter [37], NOx and soot emissions in diesel engine[38], prediction of emission levels using cylinder pressure [39-41] from diesel engines, cylinder pressure, $\mathrm{NOx}$ and $\mathrm{CO}_{2}$ from gasoline engine [42] and neural network for $\mathrm{Cl}$ and $\mathrm{SI}$ engines for predicting mainly emissions [36-50]. This is not an exhaustive list but a few very studies relevant to current work. Therefore, it is a proven case that neural network and machine learning algorithms are an excellent choice for predicting real-time engine out or tailpipe-out emission levels. However, up to date very limited literature could be found in the published domain regarding a suitable model that uses in-cylinder combustion characteristics to predict combustion generated nano-scale PM, especially, the distribution of different particle size range from gasoline engine. Hence, it is the scope of the current work.

\section{Experiments}

Experiments were carried out at a fully warmed up engine with steady state operating conditions. Each measurement lasted 20 minutes after oil and coolant temperatures reached steady state condition. Engine out PM concentrations were measured using DMS500 particle spectrometer with the measurement range of 5 to $1000 \mathrm{~nm}$. Three independent measurements were carried out on separate days in order to assess the repeatability of the experiments. Cylinder pressure was logged with $1^{\circ}$ crank angle interval simultaneously while particulate measurements are being carried out. The authors' previous work has demonstrated that a fixed dilution ratio of 125 was the optimum dilution ratio [51] and thus the fixed dilution ratio of 125 was selected for this experiment [7]. Table 1 shows the specification of the experimental engine and Table 2 shows the experimental conditions and the number of cycles of in-cylinder pressure collected simultaneously with the particulate measurement.

Table 1 Experimental engine technical specifications

\begin{tabular}{|l|l|}
\hline Bore & $77 \mathrm{~mm}$ \\
\hline Stroke & $85.8 \mathrm{~mm}$ \\
\hline Displacement & $1598 \mathrm{cc}$ \\
\hline Compression ratio & 10.5 \\
\hline Rated Power & $129 \mathrm{~kW} @ 6000 \mathrm{rev} / \mathrm{min}$ \\
\hline Rated Torque & $240 \mathrm{Nm} @ 1600$ to $5000 \mathrm{rev} / \mathrm{min}$ \\
\hline
\end{tabular}

\section{Principal Component Analysis for Cylinder Pressure}

There were 37 tests in total, which included 4 different loads and 3 different speeds as listed in Table 2. This work employed principal component analysis to identify the feature vectors of cylinder pressure [52]. These feature vectors were used to predict the number count of engine-out, combustion generated, nano-scale PM from a GDI engine. Principal Component Analysis (PCA) is a widely used technique when it comes to pattern recognition or machine learning in the research area of computer vision. The following equation describes principal component analysis mathematically; 


$$
X=\sum_{n=1}^{N} c_{n} * p_{n}+e=C * P+e
$$

where $X \in R^{M}$ is the original data set and $M$ is the dimension of the original data, $P=\left[p_{1} p_{2} p_{3} \cdots p_{N}\right]$ is the basis vector space consists of $N$ principal components $p_{1}$ to $p_{N}, C$ is the vector consists of $N$ coefficients where each one of them corresponds to each principal component and $e$ is the error. If the error is minimized, the original dataset can be represented by these $N$ coefficients. This is extremely useful for reducing the dimensionality of the large data set when $N<<M$, for instance, a 4-stroke cycle comprises 720 points can be easily transformed to under 10 coefficients without compromising the fidelity. To specifically make this investigation combustion-oriented, instead of using the full cycle to do the principal component analysis, the crank angle range from $-30^{\circ}$ to $49^{\circ}$ ATDC was chosen, for $1^{\circ}$ sampling interval, this would yield 80 points per cycle.

PCA can either be done via the Python package module which is based on the Nonlinear Iterative Partial Least Squares (NIPALS) algorithm to find the eigenvectors, or in $\mathrm{MATLAB}^{\odot}$, where the built-in PCA function works with Singular Value Decomposition (SVD). Figure 1 shows the first 8 principal components obtained by MATLAB ${ }^{\odot}$, it should be noted that these components are orthonormal vectors. The first 4 components on the upper side are the main components and represents the overall shapes of in-cylinder pressure curves. The last 4 components on the lower side have generally less influence to the shapes of the curves and are more related to the fluctuation of the cylinder pressure in higher frequency. Figure 2 shows the Root Mean Square error between the reconstructed pressure data using the 8 principal components with their correspondent coefficients and the original data. The deviation is very small, which implies that the coefficients represent well the in-cylinder pressure data.

Table 2 The speed and load conditions of all the in-cylinder pressure data

\begin{tabular}{|c|c|c|c|c|}
\hline Speed & Load & $\begin{array}{c}\text { Number of } \\
\text { tests }\end{array}$ & $\begin{array}{c}\text { Number of total } \\
\text { cycles }\end{array}$ & $\begin{array}{c}\text { Number of averaged cycles } \\
\text { for each minute }\end{array}$ \\
\hline 1500 & 20 & 4 & 56600 & 76 \\
\hline 1500 & 50 & 3 & 31495 & 52 \\
\hline 1500 & 80 & 4 & 36812 & 33 \\
\hline 1500 & 110 & 3 & 22816 & 34 \\
\hline 2500 & 20 & 3 & 39339 & 36 \\
\hline 2500 & 50 & 3 & 39351 & 27 \\
\hline 2500 & 80 & 3 & 42450 & 27 \\
\hline 2500 & 110 & 3 & 37716 & 36 \\
\hline 3500 & 20 & 3 & 42450 & 5 \\
\hline 3500 & 50 & 3 & 42450 & 437 \\
\hline 3500 & 80 & 4 & 56600 & 34 \\
\hline 3500 & 110 & 1 & 7736 & 455815 \\
\hline
\end{tabular}



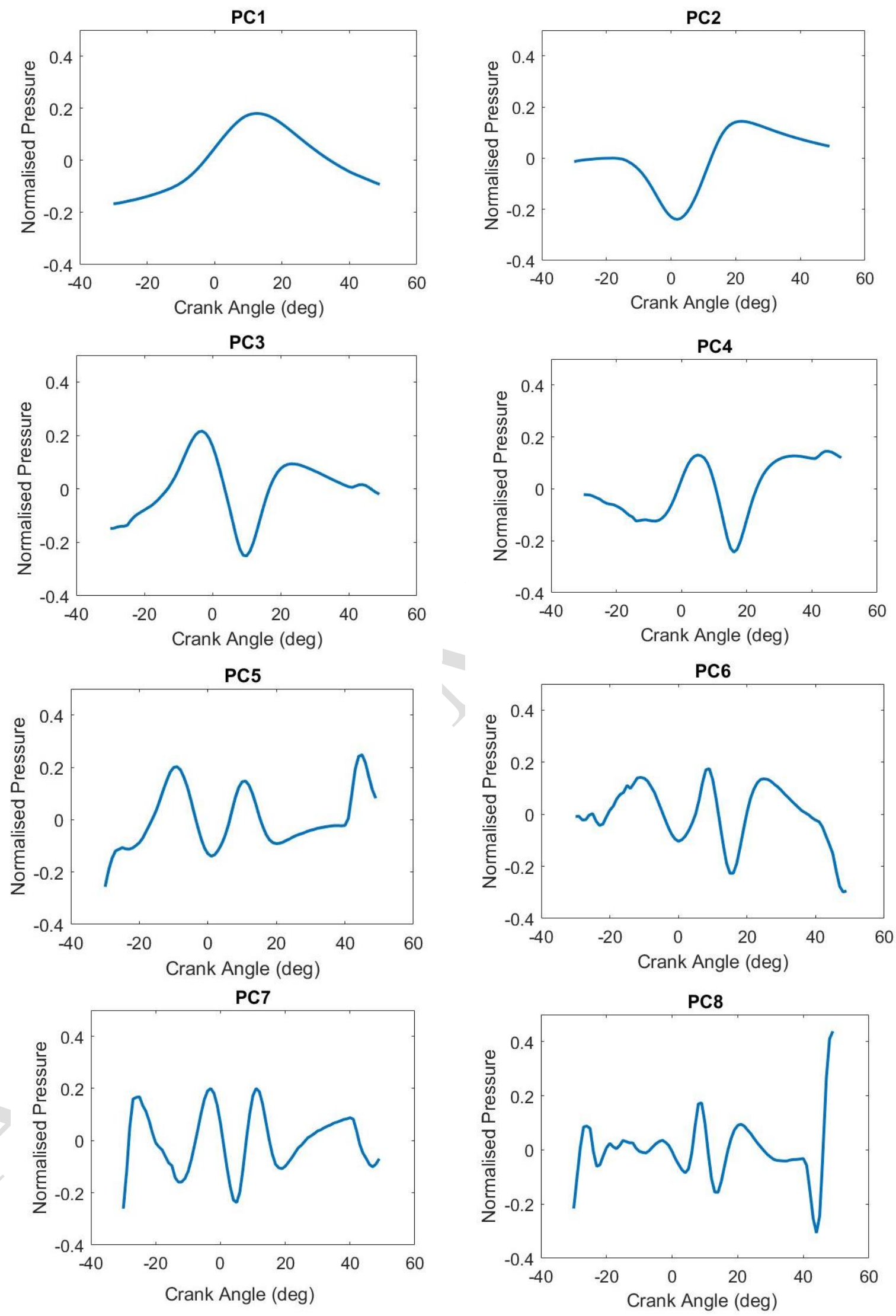

Figure 1 The first 8 principal component calculated by MATLAB ${ }^{\odot}$ 


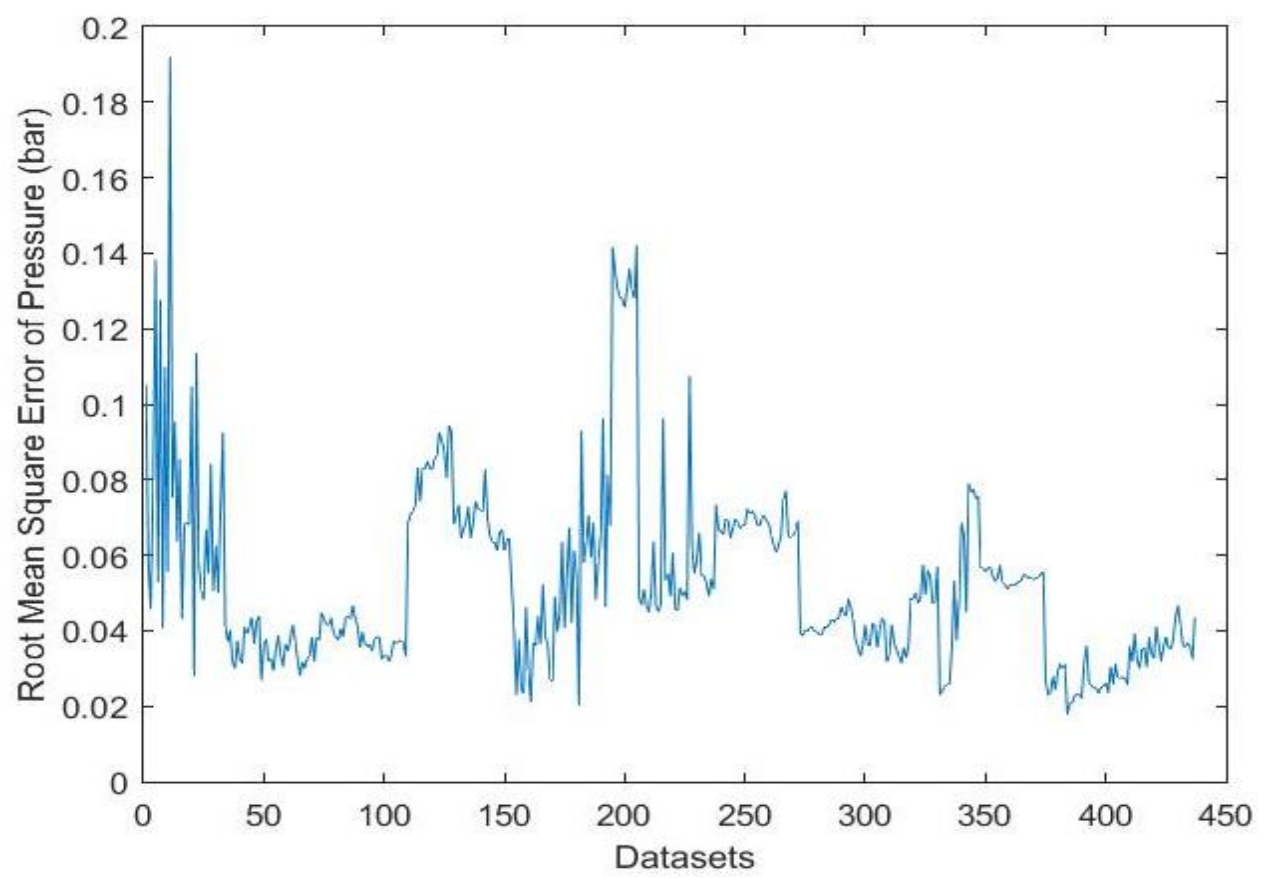

Figure 2 The root mean square error between measured pressures and the calculated pressures reconstructed by the coefficients and principal components shown in Figure 1.

\section{Neural Network - Experimental data for Neural Network}

Predicting tailpipe-out PM count during transient operating conditions is immensely useful for developing a calibration procedure for meeting legislative emission targets. This work aims to establish a correlation between the combustion characteristics and combustion generated nano-scale particles based on engine-out particle count.

The response time of the particulate spectrometer currently used is about $200 \mathrm{~ms}$. However, the cylinder pressure is measured every $1^{\circ}$ of crank angle, which imply that the spectrometer is too slow to capture the transient process occurring in the engine. Therefore, instead of estimating the transient output, the cycle-resolved pressure data within one minute was averaged to represent the steady state situation. Hence, the output data, the number count of PM per minute, was directly applicable for developing prediction method based on steady state operating condition. The engine speed and loading conditions used for developing the model are shown in Table 3.

The discrepancy between the number of averaged cycles in Table 2 and number of output in Table 3 was due to the fact that pressure data and emission data are recorded with different logging interval, therefore, the principal component analysis would be based on averaged cycles and only the 419 of them were used to train the neural network model. Figure 3 depicts these 419 cycles of in-cylinder pressure data.

The output data from the model is the PM number count per minute for different size range. These size ranges were chosen based on the information available in the public domain in relation to size range closely linked to in-cylinder combustion [18], size range mostly affected by sampling condition $[31,34]$ and particle size range of interest for the Euro 6 . The particle size range considered in this study is categorized into five groups, the first one is 15 to $23.7 \mathrm{~nm}$, and the second one is 23.7 to 
$56.2 \mathrm{~nm}$, and the third one is 56.2 to $100 \mathrm{~nm}$, and the fourth one is 100 to $300 \mathrm{~nm}$, and the fifth one is 23.7 to $1000 \mathrm{~nm}$ diameter.

Table 3 The speed and load conditions of all the measured PM data

\begin{tabular}{|c|c|c|c|}
\hline Speed (RPM) & Load (Nm) & Number of tests & Number of output \\
\hline 1500 & 20 & 4 & 76 \\
\hline 1500 & 50 & 3 & 39 \\
\hline 1500 & 80 & 4 & 49 \\
\hline 1500 & 110 & 3 & 30 \\
\hline 2500 & 20 & 3 & 32 \\
\hline 2500 & 50 & 3 & 32 \\
\hline 2500 & 80 & 3 & 36 \\
\hline 2500 & 110 & 3 & 30 \\
\hline 3500 & 20 & 3 & 27 \\
\hline 3500 & 50 & 3 & 27 \\
\hline 3500 & 80 & 4 & 36 \\
\hline 3500 & 110 & 1 & 419 \\
\hline \multicolumn{2}{|r|}{ total } & 37 & 5 \\
\hline
\end{tabular}

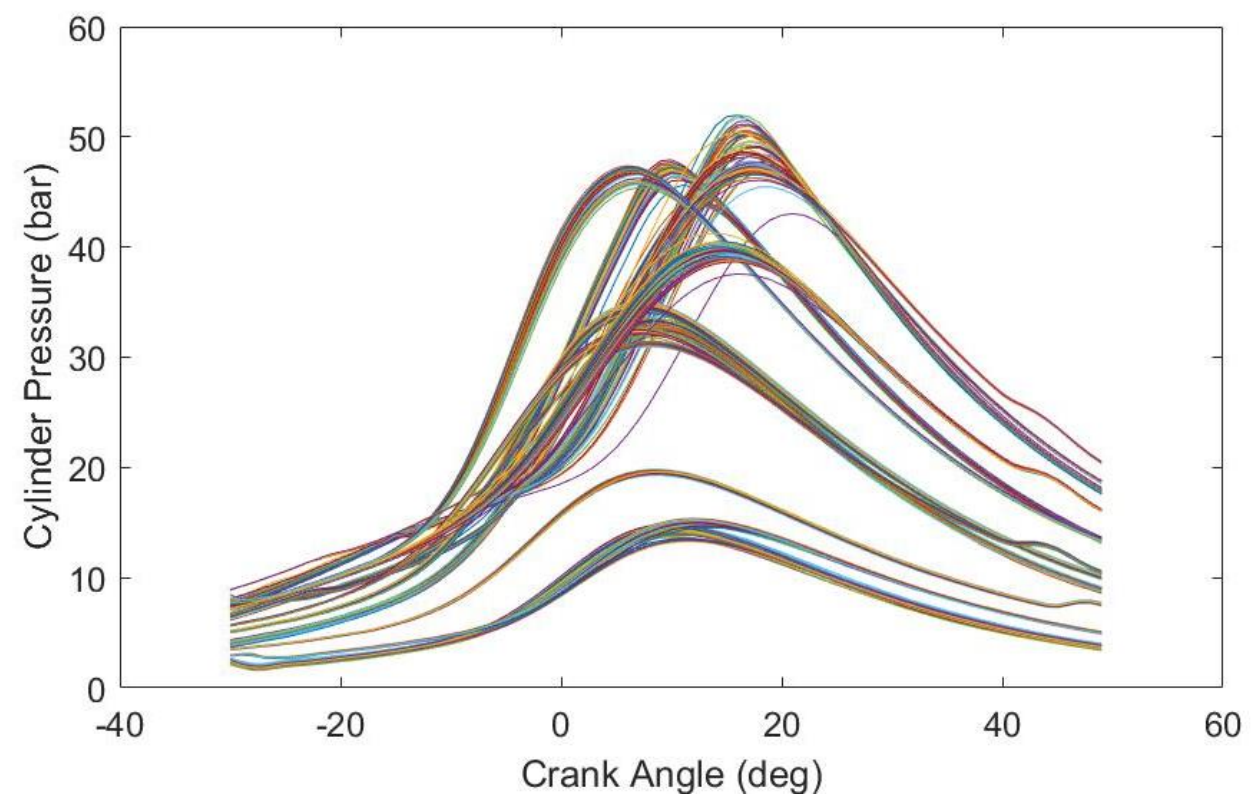

Figure 3 sample sets of cylinder pressure data used for training the neural network model

Neural network, as a widely used machine learning tool that employs the statistical method to realize the non-linear mapping. This approach will enable us to establish the correlation between two datasets and is highly suitable for modelling the process where the mathematical or physical relationship between the input and output is ambiguous and difficult to be clearly defined, such as in the case of cylinder pressure and PM emission. 
The neural network model used here is the simplest feed forward network with one hidden layer which consists of 7 nodes. Feed forward network means that the connections between these nodes form no loop. The Bayesian Regularization back propagation algorithm 'trainbr' function in MATLAB was chosen for training the network because it gave the best overall performance.

\section{Results and Validation}

Neural network model was trained to develop a correlation between the in-cylinder pressure and the number count of engine-out nano-scale PM of different size range. The overall method used for developing neural network for the prediction of engine out nano-scale PM is shown in Figure 4.

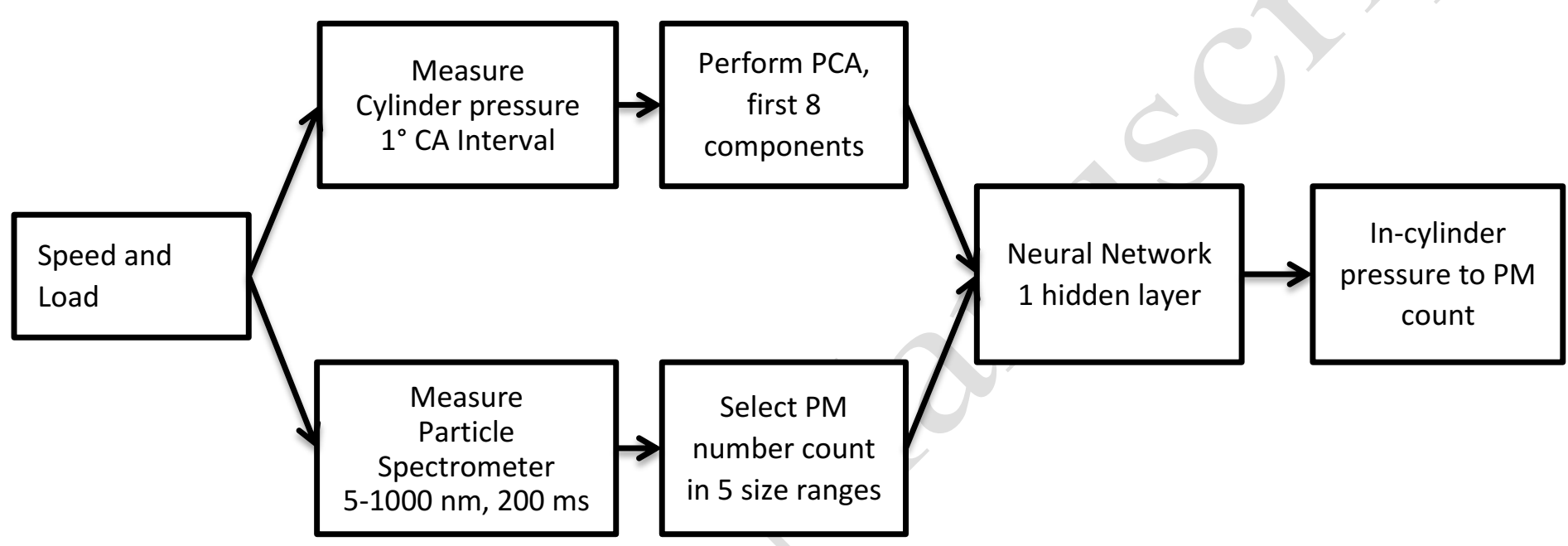

Figure 4 Overall scheme of work

The current experimental data for developing neural network for predicting engine out nano-scale PM count has 419 data sets in total. In order to find the balance between maximizing the number of datasets for training and leave representative amount of datasets for testing, $85 \%$ of the total 419 datasets, i.e. 356 datasets, were randomly chosen by the MATLAB programme for training the neural network and the remaining $15 \%$, i.e. 63 datasets, were used for testing the neural network.

Figure 5 shows the output of neural network for $15-23.7 \mathrm{~nm}$ particle size range against various engine speed and load operating conditions. The neural network model with 8 principal components from cylinder pressure with 1 hidden layer is able to predict the engine-out particle number count for this size range well with the $R^{2}$ value for testing reaches about 0.88 as shown in Figure 6. Similarly Figures 7 and 8 show the measured and predicted particle count for the size range 23.7 to 56 $\mathrm{nm}$ diameter. The $\mathrm{R}^{2}$ value for testing is about 0.89 . Figures 9 and 10 show the predicted particle count for the size range 56 to $100 \mathrm{~nm}$. The $R^{2}$ value for testing is 0.93 . Figures 11 and 12 show the predicted particle count for the size range 100-300 $\mathrm{nm}$. The $\mathrm{R}^{2}$ value for testing is 0.96 . It could be observed that as the size range increases the accuracy of prediction of also increases for the size range 15 to $300 \mathrm{~nm}$. In most cases the particle of interest in GDI engine is mainly in this size range. The number count of PM with diameters between 15 and $300 \mathrm{~nm}$ seems to be in direct correlation with the in-cylinder pressure; in other words, it could be stated that these PM are mainly combustion generated particles. 
The European legislative testing gives only $50 \%$ counting efficiency for the particle size range below 23.7 since this size range is most likely to be affected by the sampling procedure and conditions and also the higher signal to noise ratio from the measurement instrument. Therefore, the particle size range of interest for the vehicle calibration engineers is 23 to $1000 \mathrm{~nm}$ diameter. Figures 13-14 show results for the size 23.7-1000 nm which are very relevant to legislative testing and conformity of production testing. These results show very good agreement between the measured and predicted particle count for particle size range of 23.7 to $1000 \mathrm{~nm}$ diameter with the $R^{2}$ value of 0.92 . This size range seems to have very good correlation with the cylinder pressure and therefore, it could be inferred that they are combustion generated nano-scale PM. In addition, it also gives us the confidence that the models such as mean value engine models (MVEM) used for developing vehicle calibration procedures can employ this approach for developing vehicle calibration for meeting engine-out nano-scale particle count. 


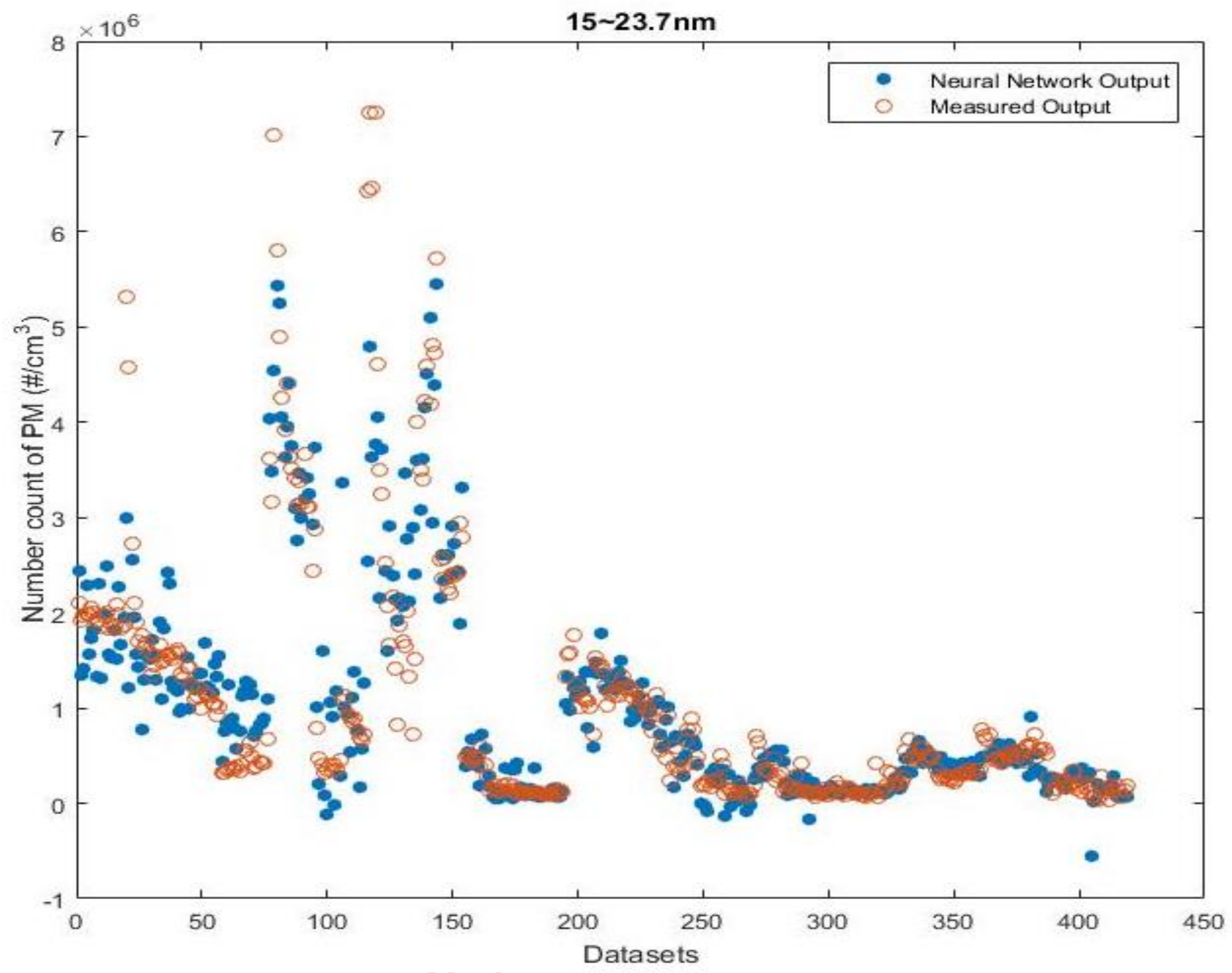

Figure 5 The comparisons of the neural network and the measured output from PM size $15 \mathrm{~nm}$ to $23.7 \mathrm{~nm}$
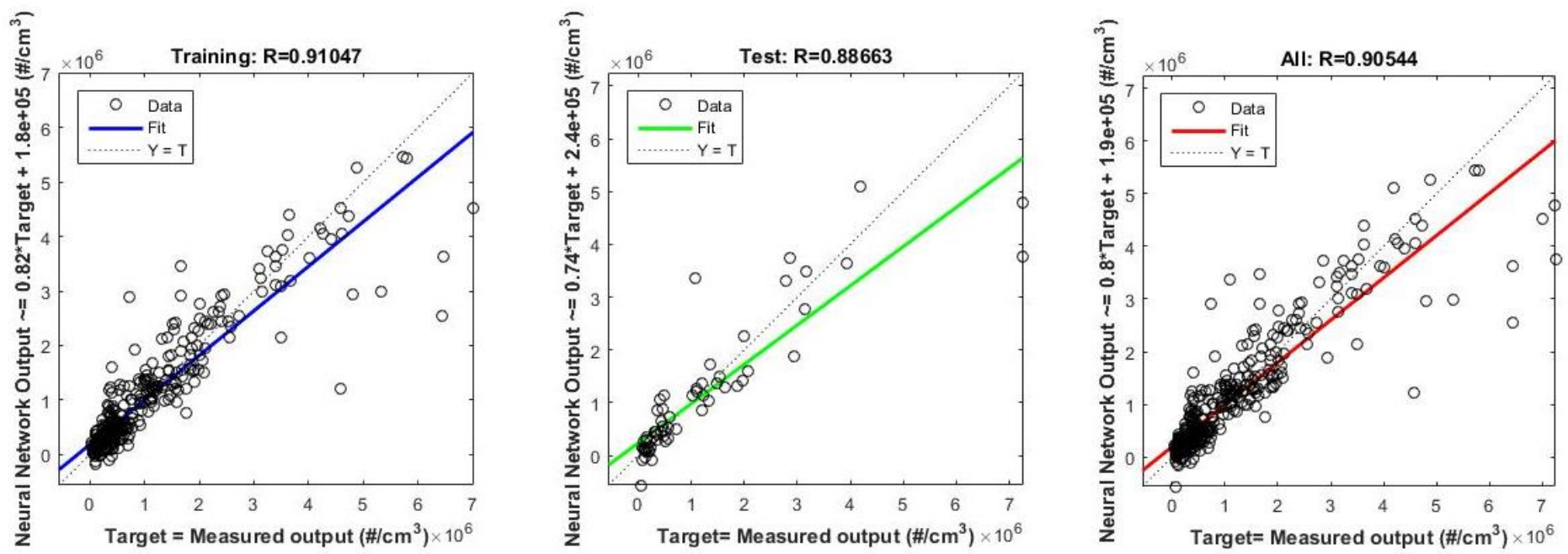

Figure 6 The regression trend for the PM size $15 \mathrm{~nm}$ to $23.7 \mathrm{~nm}$. 


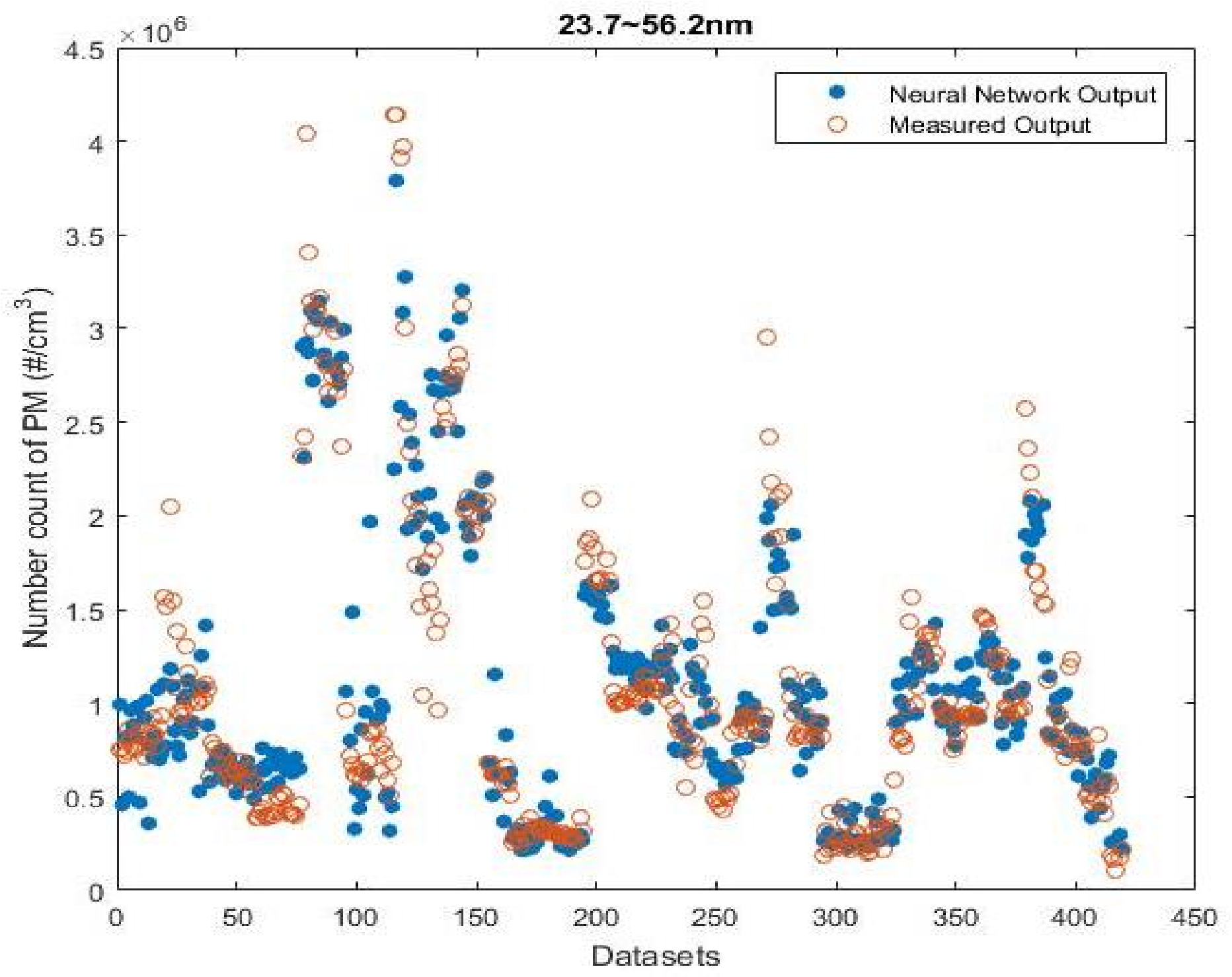

Figure 7 The comparisons of the Neural Network output and the measured output of PM size $23.7 \mathrm{~nm}$ to $56.2 \mathrm{~nm}$
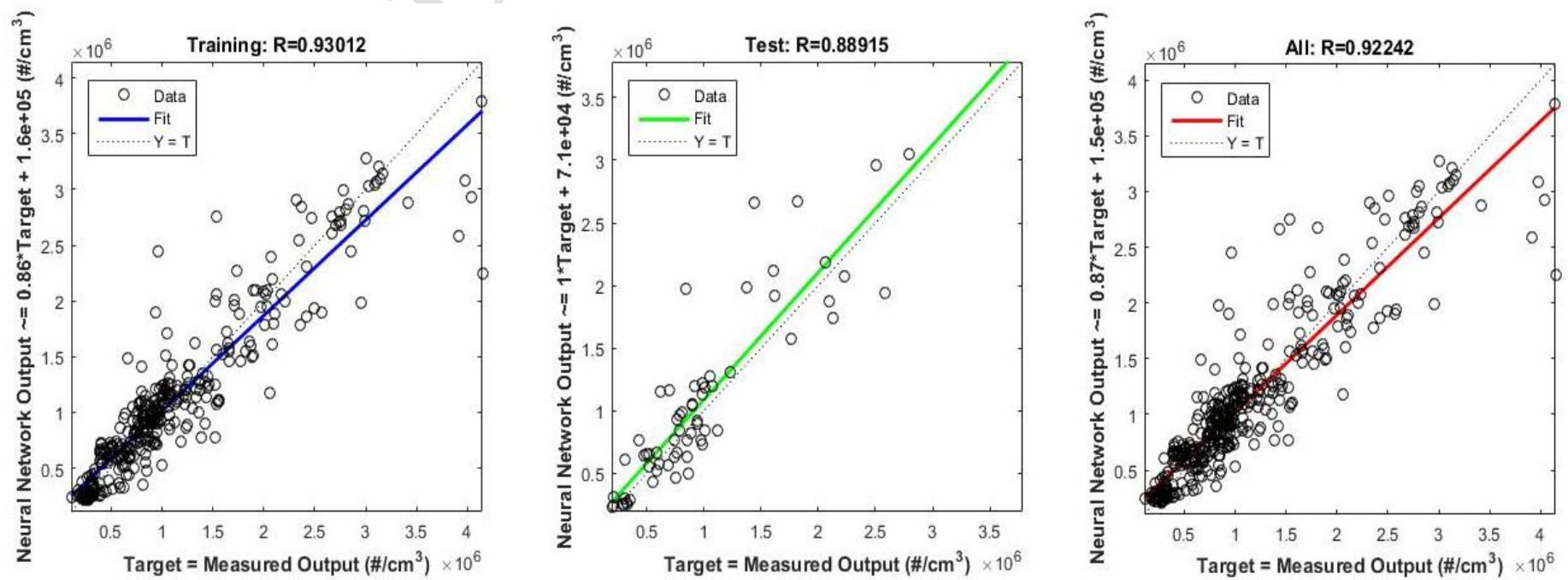

Figure 8 The regression trend for the PM size $23.7 \mathrm{~nm}$ to $56.2 \mathrm{~nm}$ 


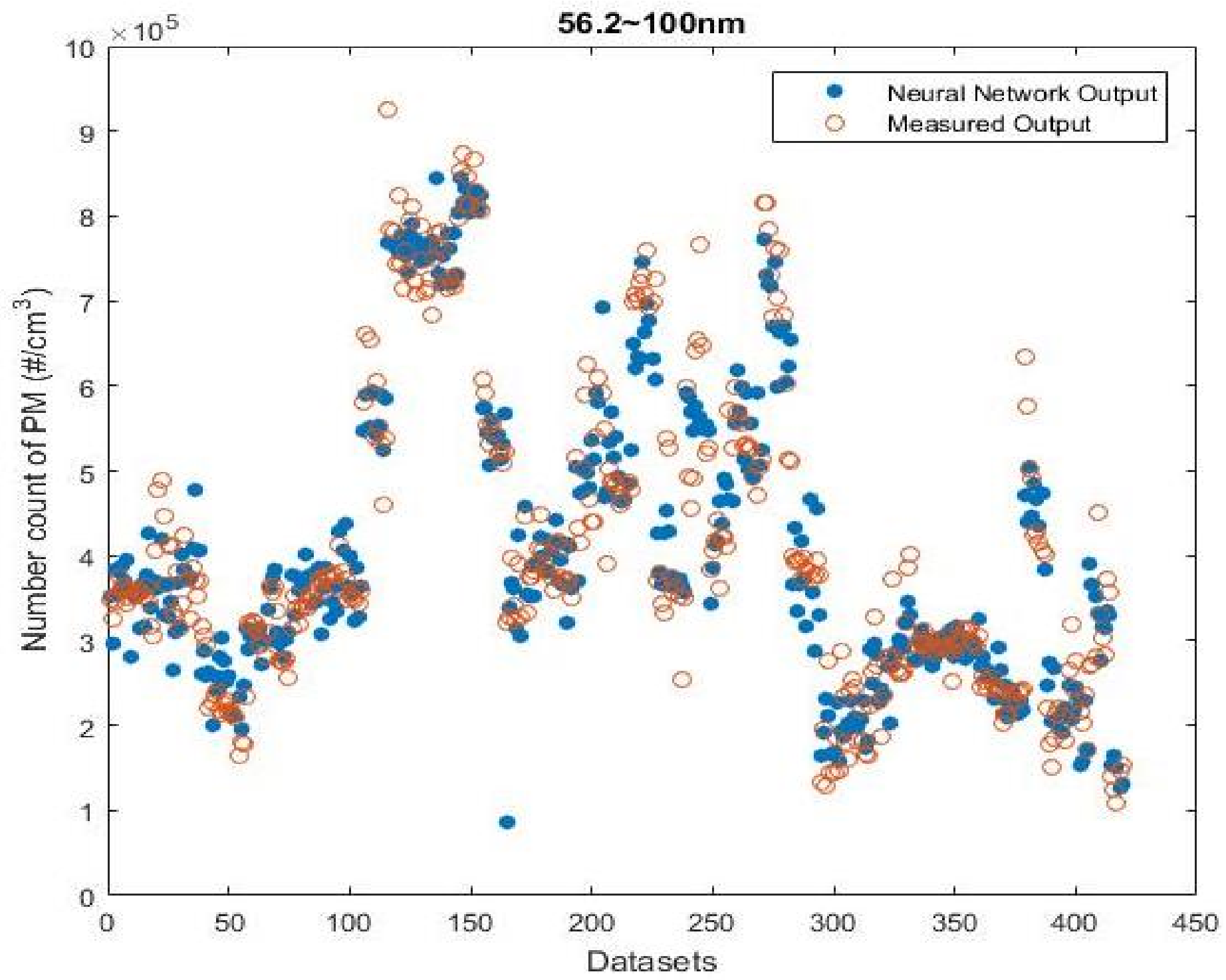

Figure 9 The comparisons of the Neural Network output and the measured output of PM size $56.2 \mathrm{~nm}$ to $100 \mathrm{~nm}$
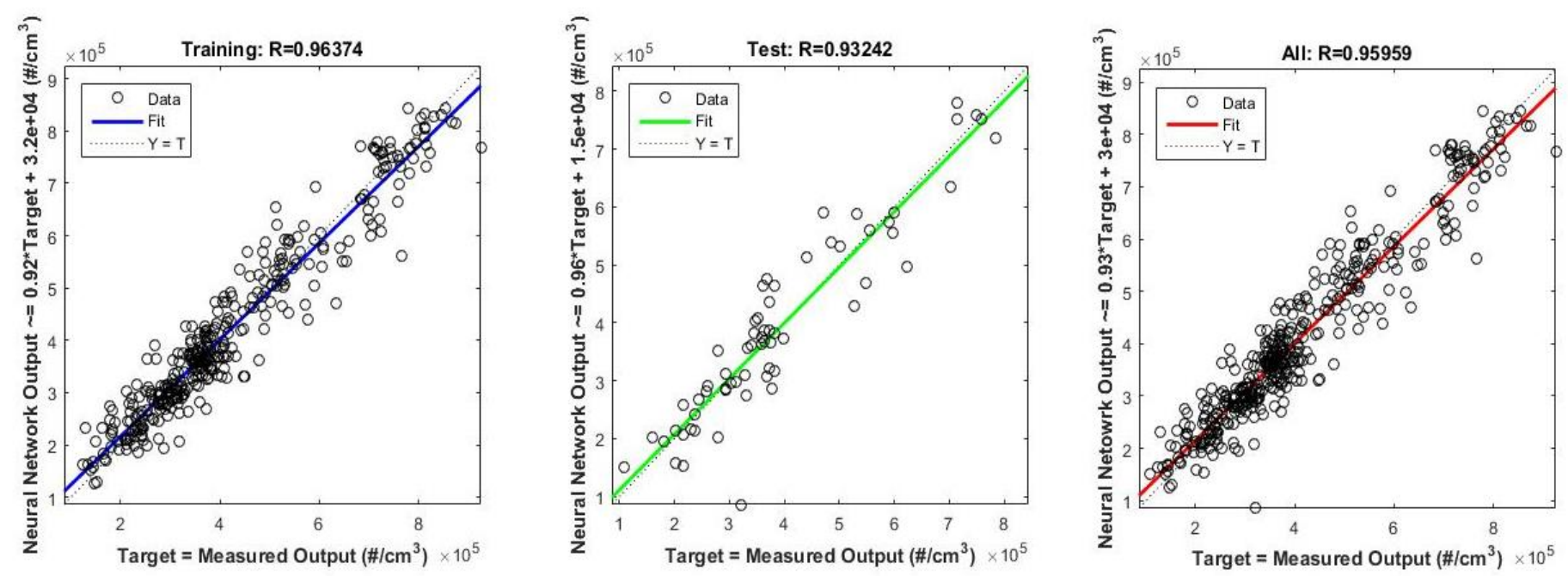

Figure 10 The regression trend for the PM size $56.2 \mathrm{~nm}$ to $100 \mathrm{~nm}$ 


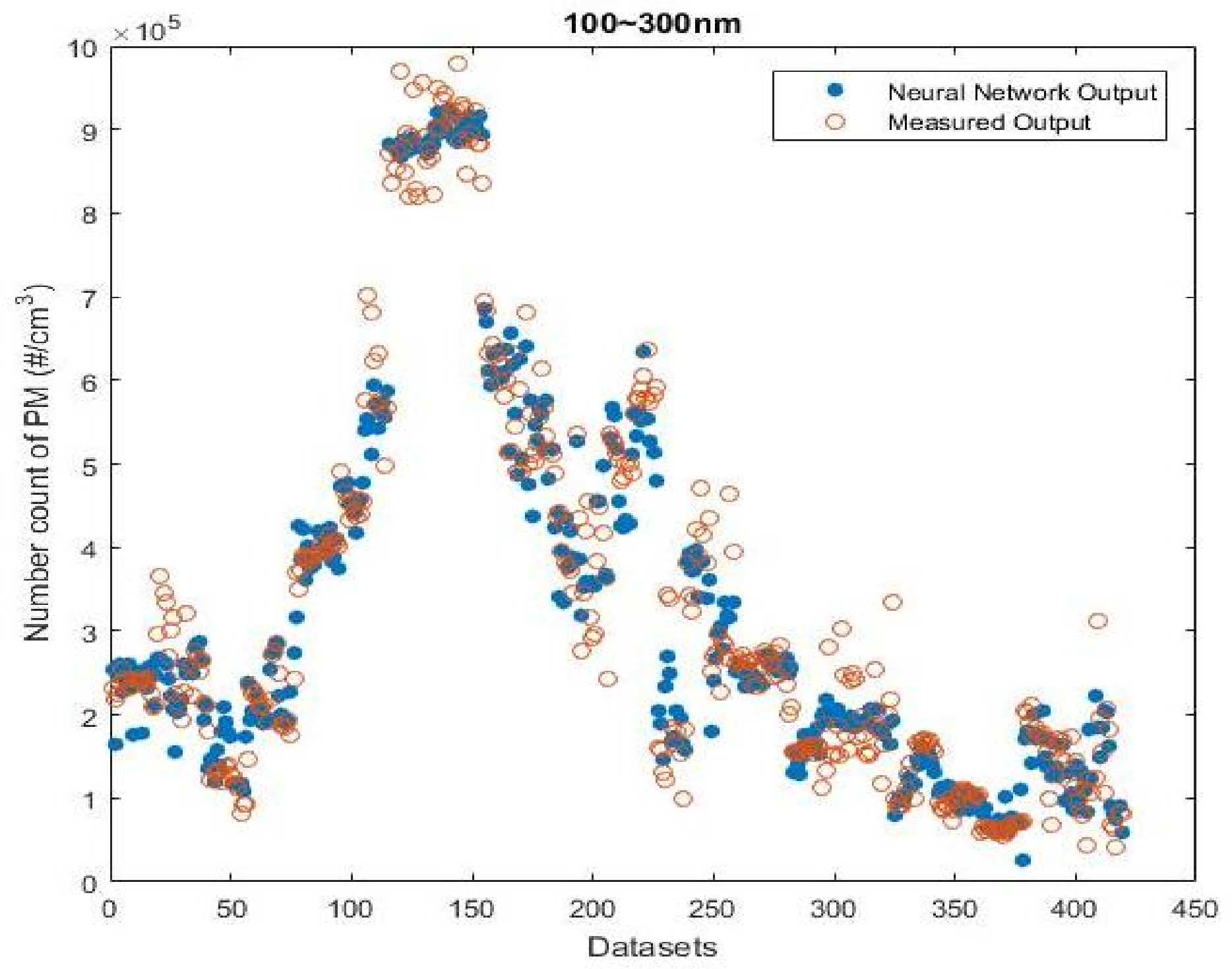

Figure 11 The comparisons of the Neural Network output and the measured output of PM size $100 \mathrm{~nm}$ to $300 \mathrm{~nm}$
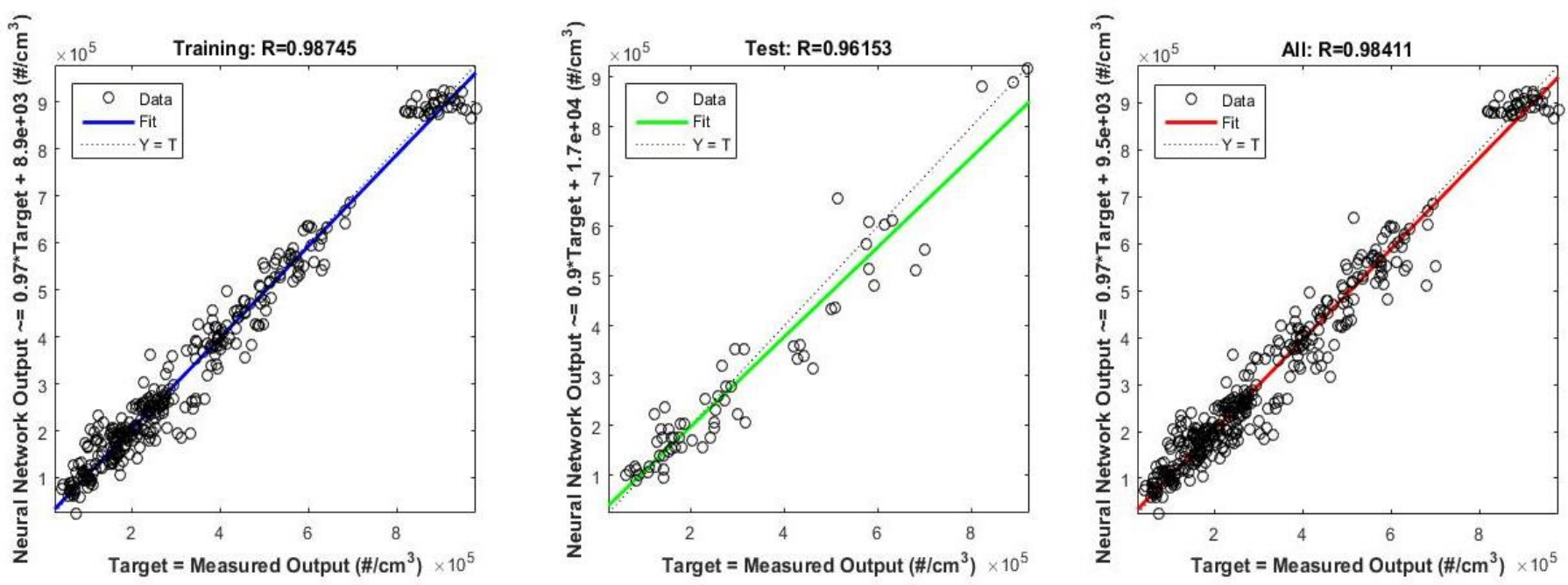

Figure 12 The regression trend for the PM size $100 \mathrm{~nm}$ to $300 \mathrm{~nm}$ 


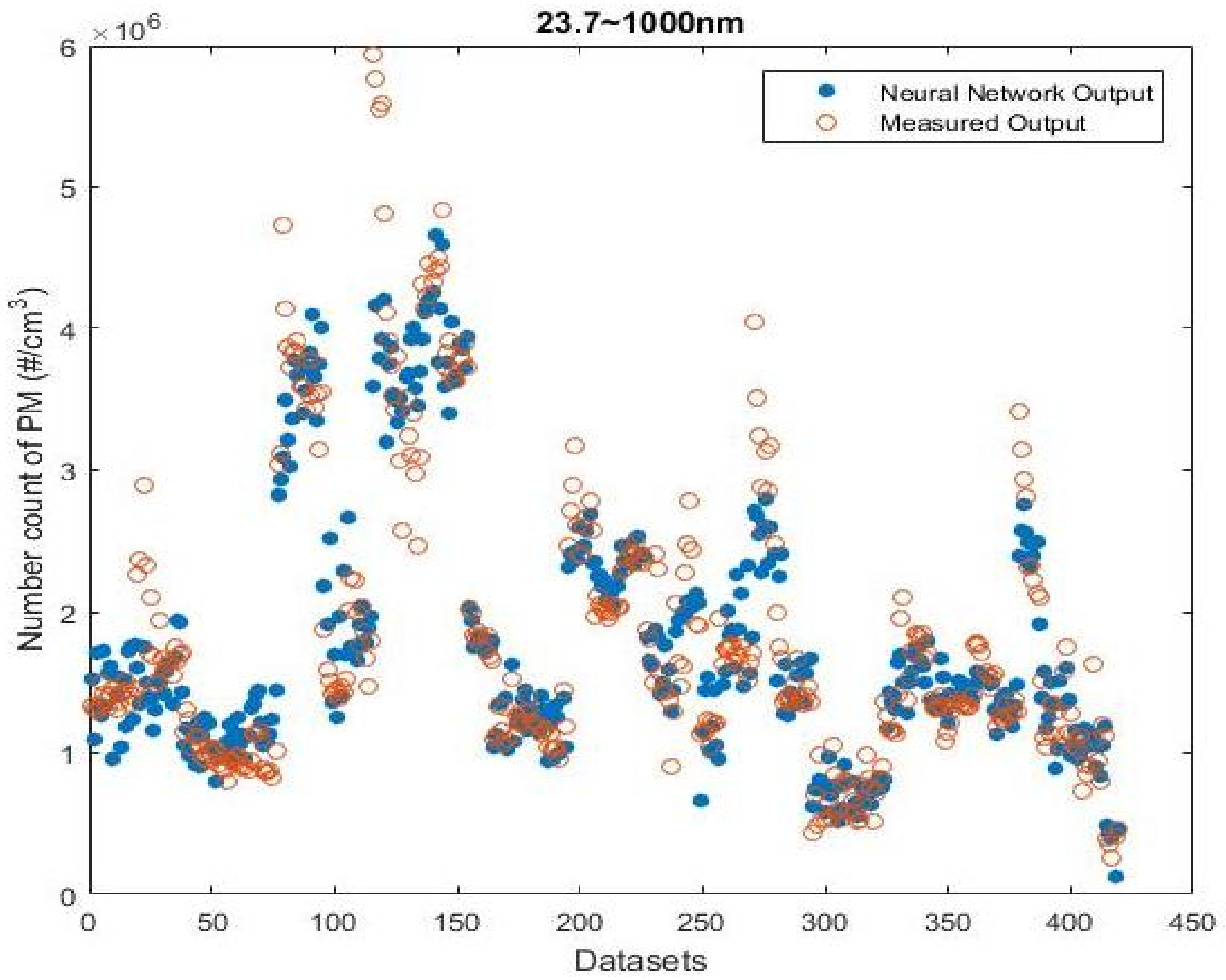

Figure 13 The comparisons of the Neural Network output and the measured output of PM size $23.7 \mathrm{~nm}$ to $1000 \mathrm{~nm}$
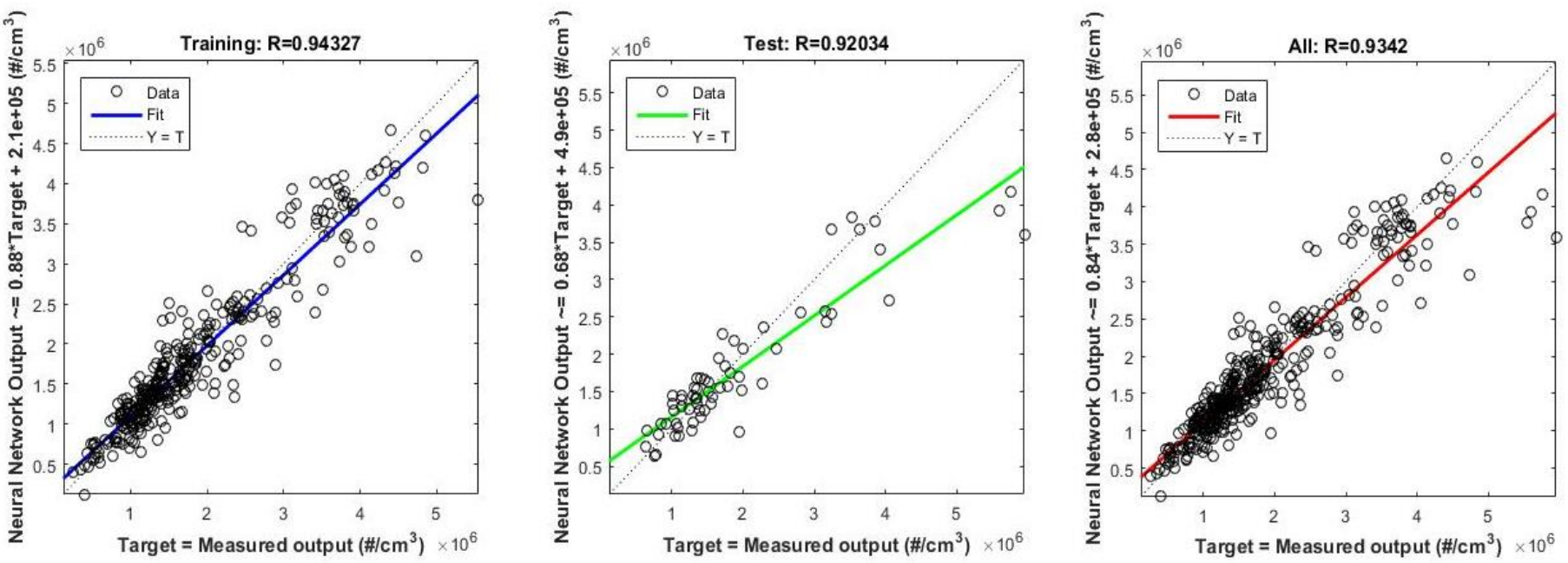

Figure 14 The regression analysis for the PM size $23.7 \mathrm{~nm}$ to $1000 \mathrm{~nm}$ 


\section{Conclusions}

This work employed PCA for extracting feature vectors of cylinder pressure from a Euro-IV, spark-ignited, turbocharged and intercooled GDI engines. It identified that the first 8 principal components are sufficient for representing in-cylinder combustion characteristics for the purpose of this work.

It also demonstrated that a simple neural network model with only one hidden layer is sufficient for training and predicting the number of engine-out nano-scale particle size in the range of 15 to $1000 \mathrm{~nm}$ diameter. The agreement between the number count of predicted PM and measured PM was found to improve for the larger particles in the examined range.

The predicted and measured particle count for the particle size range of interest, 23.7 to $1000 \mathrm{~nm}$, has reasonable level of agreement with $\mathrm{R}^{2}$ value of about 0.93 . Therefore, the approach to represent the engine loading conditions with cylinder pressure can be utilised in mean value engine models (MVEM) which are commonly used for vehicle calibration.

\section{References}

[1] A. Faiz, W. S. Christopher., and W. P. Michael., "Air Pollution from Motor Vehicle, Standards and Technologies for Controlling Emissions.," ISBN 0-8213-3444-1, 1996.

[2] 70/220/EEC, "Council Directive 70/220/EEC of 20 March 1970 on the approximation of the laws of the Member States relating to measures to be taken against air pollution by gases from positive-ignition engines of motor vehicles," ed: EU-Lex, 1970.

[3] S. Samuel et al., "Real-world fuel economy and emission levels of a typical EURO-IV passenger vehicle," Proceedings of the Institution of Mechanical Engineers Part D-Journal of Automobile Engineering, vol. 219, no. D6, pp. 833-842, JUN 2005 2005 .

[4] 72/306/EEC, "COUNCIL DIRECTIVE of 2 August 1972 on the approximation of the laws of the Member States relating to the measures to be taken against the emission of pollutants from diesel engines for use in vehicles (72/306/EEC)," ed, 1972.

[5] 88/77/EEC, "Proposal for a European Parliament and Council Directive amending Council Directive 88/77/EEC on the approximation of the laws of the Member States relating to the measures to be taken against the emission of gaseous and particulate pollutants from diesel engines for use in vehicles, $/ *$ COM/97/0627 final - COD 97/0350 */," ed, 1988.

[6] 98/70/EC, "Commission staff working document - Accompanying document to the Proposal for a directive of the European Parliament and of the Council amending Directive 98/70/EC as regards the specification of petrol, diesel and gas-oil and introducing a mechanism to monitor and reduce greenhouse gas emissions from the use of road transport fuels and amending Council Directive 1999/32/EC, as regards the specification of fuel used by inland waterway vessels and repealing Directive 93/12/EEC - Impact Assessment - $\operatorname{COM}(2007) 18$ final $\}$ - $\{\mathrm{SEC}(2007) 56\}, "$ ed, 1998.

[7] I. Whelan, S. Samuel, D. Timoney, and A. Hassaneen, "Characteristics of Nano-Scale Particulates from Gasoline Turbo-Intercooled Direct-Injection Engine," SAE Int. J. Fuels Lubr., vol. 3, no. 2, pp. 839-848, 2010.

[8] D. B. Kittelson, "Engines and nanoparticles: a review," Journal of Aerosol Science, vol. 29, no. 5-6, pp. 575-588, 6/1/ 1998.

[9] W. G. Kreyling, M. Semmler-Behnke, and W. Moller, "Ultrafine particle-lung interactions: does size matter?," (in eng), $J$ Aerosol Med, vol. 19, no. 1, pp. 74-83, Spring 2006.

[10] L. Künzi et al., "Toxicity of aged gasoline exhaust particles to normal and diseased airway epithelia," Scientific Reports, Article vol. 5, p. 11801, 06/29/online 2015.

[11] E. 715/2007, "REGULATION (EC) No 715/2007 OF THE EUROPEAN PARLIAMENT AND OF THE COUNCIL

of 20 June 2007 on type approval of motor vehicles with respect to emissions from light passenger and commercial vehicles (Euro 5 and Euro 6) and on access to vehicle repair and maintenance information,29.6.2007 EN Official Journal of the European Union L 171/1.," ed, 2007.

[12] D. Kayes and S. Hochgreb, "Mechanisms of Particulate Matter Formation in Spark-Ignition Engines. 1. Effect of Engine Operating Conditions," Environmental Science \& Technology, vol. 33, no. 22, pp. 3957-3967, 1999/11/01 1999.

[13] D. Kayes, S. Hochgreb, M. M. Maricq, D. H. Podsiadlik, and R. E. Chase, "Particulate Matter Emission During Start-up and Transient Operation of a Spark-Ignition Engine (2): Effect of Speed, Load, and Real-World Driving Cycles," 2000. Available: http://dx.doi.org/10.4271/2000-01-1083

[14] X. He, M. A. Ratcliff, and B. T. Zigler, "Effects of Gasoline Direct Injection Engine Operating Parameters on Particle Number Emissions," Energy \& Fuels, vol. 26, no. 4, pp. 2014-2027, 2012/04/19 2012.

[15] Q. Jiao and R. D. Reitz, "The Effect of Operating Parameters on Soot Emissions in GDI Engines," SAE Int. J. Engines, vol. 8, no. 3, pp. 1322-1333, 2015. 
[16] I. Whelan, S. Samuel, and A. E. Hassaneen, "The Effect of Fuel Temperature on Particulate Matter Formation in Gasoline Direct-Injection Engines," SAE Int. J. Fuels Lubr., vol. 3, no. 2, pp. 67-76, 2010.

[17] A. E. Hassaneen, S. Samuel, and I. Whelan, "Combustion instabilities and nanoparticles emission fluctuations in GDI spark ignition engine," International Journal of Automotive Technology, vol. 12, no. 6, pp. 787-794, DEC 20112011.

[18] A. E. Hassaneen, S. Samuel, D. Morrey, and R. Gonzalez-Oropeza, "Influence of Physical and Chemical Parameters on Characteristics of Nano-scale Particulate in Spark Ignition Engine," 2009. Available: http://dx.doi.org/10.4271/2009-01-2651

[19] C. Tan, H. Xu, H. Ma, and A. Ghafourian, "Investigation of VVT and spark timing on combustion and particle emission from a GDI Engine during transient operation," 2014. Available: http://dx.doi.org/10.4271/2014-01-1370

[20] M. Matti Maricq, R. H. Munoz, J. Yang, and R. W. Anderson, "Sooting Tendencies in an Air-Forced Direct Injection Spark-Ignition (DISI) Engine," 2000. Available: http://dx.doi.org/10.4271/2000-01-0255

[21] M. Hedge, P. Weber, J. Gingrich, T. Alger, and I. A. Khalek, "Effect of EGR on Particle Emissions from a GDI Engine," 2011.

[22] T. Alger, J. Gingrich, I. A. Khalek, and B. Mangold, "The Role of EGR in PM Emissions from Gasoline Engines," SAE Int. J. Fuels Lubr., vol. 3, no. 1, pp. 85-98, 2010.

[23] I. Arsie, S. Di Iorio, and S. Vaccaro, "Experimental investigation of the effects of AFR, spark advance and EGR on nanoparticle emissions in a PFI SI engine," Journal of Aerosol Science, vol. 64, pp. 1-10, 10// 2013.

[24] T. Lattimore, C. Wang, H. Xu, M. L. Wyszynski, and S. Shuai, "Investigation of EGR Effect on Combustion and PM Emissions in a DISI Engine," Applied Energy, vol. 161, pp. 256-267, 1/1/ 2016.

[25] K. Choi et al., "Effect of the mixture preparation on the nanoparticle characteristics of gasoline direct-injection vehicles," Proceedings of the Institution of Mechanical Engineers, Part D: Journal of Automobile Engineering, vol. 226, no. 11, pp. 1514-1524, 2012/11/012012.

[26] C. Wang, H. Xu, J. M. Herreros, J. Wang, and R. Cracknell, "Impact of fuel and injection system on particle emissions from a GDI engine," Applied Energy, vol. 132, pp. 178-191, 11/1/ 2014.

[27] I. Whelan, Samuel, S., and Hassaneen, A., "'Investigation into the Role of Catalytic Converters on Tailpipe-out Nano-Scale Particulate Matter from Gasoline Direct Injection Engine," 2010, doi:10.4271/2010-01-1572.," ed: SAE, 2010.

[28] S. Samuel, A. Hassaneen, and D. Morrey, "Particulate Matter Emissions and the Role of Catalytic Converter During Cold Start of GDI Engine," 2010. Available: http://dx.doi.org/10.4271/2010-01-2122

[29] M. Cucchi and S. Samuel, "Influence of the exhaust gas turbocharger on nano-scale particulate matter emissions from a GDI spark ignition engine," Applied Thermal Engineering, vol. 76, pp. 167-174, 2/5/ 2015.

[30] M. Cucchi and S. Samuel, "Application of the Lambert W function for the impact of the exhaust gas turbocharger on nanoscale PM emissions from a TGDI engine," Applied Thermal Engineering, vol. 99, pp. 429-433, 4/25/ 2016.

[31] Z. Zheng et al., "Nature of Sub-23-nm Particles Downstream of the European Particle Measurement Programme (PMP)-Compliant System: A Real-Time Data Perspective," Aerosol Science and Technology, vol. 46, no. 8, pp. 886-896, 2012/08/01 2012.

[32] D. Kayes and S. Hochgreb, "Investigation of the Dilution Process for Measurement of Particulate Matter from Spark-Ignition Engines," 1998. Available: http://dx.doi.org/10.4271/982601

[33] B. Giechaskiel et al., "Review of motor vehicle particulate emissions sampling and measurement: From smoke and filter mass to particle number," Journal of Aerosol Science, vol. 67, pp. 48-86, 1// 2014.

[34] Z. Zheng et al., "Investigation of solid particle number measurement: Existence and nature of sub-23 nm particles under PMP methodology," Journal of Aerosol Science, vol. 42, no. 12, pp. 883-897, 12// 2011.

[35] R. o. UN/ECE, "Regulation No 49 of the Economic Commission for Europe of the United Nations (UN/ECE) Official Journal of the European Union,L 180/53,2010 amendments to Regulation 49 published in OJ L 103, 12.4.2008, p. 1. —Uniform provisions concerning the measures to be taken against the emission of gaseous andparticulate pollutants from compression-ignition engines for use in vehicles, and the emission ofgaseous pollutants from positive-ignition engines fuelled with natural gas or liquefied petroleum gasfor use in vehicles," UN/ECE, Ed., ed, 2010.

[36] F. T. Scafati, N. Cesario, M. Lavorgna, S. S. Merola, and B. M. Vaglieco, "Soft Computing Model for Prediction of EGR Effects on Particle Sizing at CR Diesel Engine Exhaust," 2007. Available: http://dx.doi.org/10.4271/2007-24-0104

[37] D. J. Kapparos, I. Brahma, A. Strzelec, C. J. Rutland, D. E. Foster, and Y. He, "Integration of Diesel Engine, Exhaust System, Engine Emissions and Aftertreatment Device Models," 2005. Available: http://dx.doi.org/10.4271/2005-01-0947

[38] Y. He and C. J. Rutland, "Modeling of a Turbocharged DI Diesel Engine Using Artificial Neural Networks," 2002. Available: http://dx.doi.org/10.4271/2002-01-2772

[39] V. M. Janakiraman, S. Suryanarayanan, G. L. N. Rao, and S. Sampath, "Prediction of CI Engine Emissions from Combustion Chamber Pressure Characteristics," 2007. Available: http://dx.doi.org/10.4271/2007-01-1121

[40] V. M. Janakiraman, S. Suryanarayanan, S. Saravanan, and G. L. N. Rao, "Analysis of the Effect of In-cylinder Parameters on NOX and HC Emissions of a CI Engine Using Artificial Neural Networks," 2006. Available: http://dx.doi.org/10.4271/2006-01-3313

[41] V. M. Janakiraman, S. Suryanarayanan, G. L. N. Rao, and S. Sampath, "Estimation of Engine Emissions Based on Physical and Chemical Properties of Biodiesels using Artificial Neural Networks," 2006. Available: http://dx.doi.org/10.4271/2006-01-3533

[42] G. Anand, S. Gopinath, M. R. Ravi, I. N. Kar, and J. P. Subrahmanyam, "Artificial Neural Networks for Prediction of Efficiency and NOx Emission of a Spark Ignition Engine," 2006. Available: http://dx.doi.org/10.4271/2006-01-1113

[43] S. M, M. Zoppi, P. Nithiarasu, D. V. Kumar, P. R. Kumar, and M. S. Kumari, "International Conference on Design and Manufacturing (IConDM2013)Prediction of Performance and Emissions of a Biodiesel Fueled Lanthanum Zirconate Coated 
Direct Injection Diesel Engine Using Artificial Neural Networks," Procedia Engineering, vol. 64, pp. 993-1002, 2013/01/01 2013.

[44] J. Wang, Y. Zhang, Q. Xiong, and X. Ding, "NOx Prediction by Cylinder Pressure Based on RBF Neural Network in Diesel Engine," in 2010 International Conference on Measuring Technology and Mechatronics Automation, 2010, vol. 2, pp. $792-795$.

[45] X. Yong, H. Guiyou, S. Chunrong, N. Zhibing, and Z. Wu, "Reconstruction of Cylinder Pressure of I.C. Engine Based on Neural Networks," in Pervasive Computing Signal Processing and Applications (PCSPA), 2010 First International Conference on, 2010, pp. 924-927.

[46] A. J. C. Sharkey, G. O. Chandroth, and N. E. Sharkey, "Acoustic emission, cylinder pressure and vibration: a multisensor approach to robust fault diagnosis," in Neural Networks, 2000. IJCNN 2000, Proceedings of the IEEE-INNS-ENNS International Joint Conference on, 2000, vol. 6, pp. 223-228 vol.6.

[47] N. Wickstrom, M. Taveniku, A. Linde, M. Larsson, and B. Svensson, "Estimating pressure peak position and air-fuel ratio using the ionization current and artificial neural networks," in Intelligent Transportation System, 1997. ITSC '97., IEEE Conference on, 1997, pp. 972-977.

[48] M. L. Traver, R. J. Atkinson, and C. M. Atkinson, "Neural Network-Based Diesel Engine Emissions Prediction Using In-Cylinder Combustion Pressure," 1999. Available: http://dx.doi.org/10.4271/1999-01-1532

[49] J. M. Desantes, J. J. López, J. M. García, and L. Hernández, "Application of Neural Networks for Prediction and Optimization of Exhaust Emissions in a H.D. Diesel Engine," 2002. Available: http://dx.doi.org/10.4271/2002-01-1144

[50] A. H. Gadallah, E. A. Elshenawy, A. M. Elzahaby, H. A. El-Salmawy, and A. H. Bawady, "Application of Neural Networks for Prediction and Optimization of Emissions and Performance in a Hydrogen Fuelled Direct Injection Engine Equipped With In Cylinder Water Injection," 2009. Available: http://dx.doi.org/10.4271/2009-01-2684

[51] I. Whelan, D. Timoney, W. Smith, and S. Samuel, "The Effect of a Three-Way Catalytic Converter on Particulate Matter from a Gasoline Direct-Injection Engine During Cold-Start," 2013. Available http://doi.org/10.4271/2013-01-1305

[52] M. Henningsson, B. Bernhardsson, P. Tunestal, and R. Johansson, "A Machine Learning Approach to Information Extraction from Cylinder Pressure Sensors," 2012. Available: http://dx.doi.org/10.4271/2012-01-0440 